\title{
VOCÊ CONHECE ESSE TAL THE BEATLES? \\ - DA PESQUISA À CRIAÇÃO DE UM RECITAL
}

\section{Flávia Maiara Lima Fagundes}

flaviamaiaralf@gmail.com

\section{Fernando Martins Oliveira Neto}

fernandomartinssh@gmail.com

\section{Universidade Federal do Rio Grande do Norte}

RESUMO: O recital "Você conhece esse tal The Beatles?" foi resultado das vivências musicais com as crianças do Ensino Fundamental do Núcleo de Educação da Infância NEI-CAp da UFRN. A partir de propostas musicalizadoras, que envolveram a música, o movimento e a palavra (ORFF, 1978), pudemos aproximar as crianças dos Beatles, contextualizando-as através de vivências, jogos, criação, músicas e danças. As canções foram recriadas coletivamente, partindo de sua apreciação e sua contextualização histórico-cultural. A apresentação em forma de musical foi a culminância do processo em que todos participassem não somente das apresentações, mas também da criação dos cenários, figurinos, coreografias e arranjos. $\mathrm{O}$ resultado foi uma empolgante mostra de entusiasmo, empenho e domínio dos conteúdos por parte dos alunos.

PALAVRAS-CHAVE: Educação Musical na escola básica. Tema de pesquisa. Criação coletiva.

\section{YOU KNOW THAT SUCH THE BEATLES? - FROM RESEARCH TO THE CREATION OF A RECITAL}

ABSTRACT: The recital "You know this as The Beatles?" was the result of musical experiences with children of elementary school of the Childhood Education Center -NEICAp UFRN. From musical proposals, involving music, movement and word (ORFF, 1978), we were able to bring the children of the Beatles, contextualizing them through experiences, games, creation, music and dances. The songs were collectively recreated, from its assessment and its historical and cultural context. The presentation in the form of music was the culmination of the process in which all participate not only the presentations but also the creation of sets, costumes, choreography and arrangements. The result was an exciting show of enthusiasm, commitment and the content domain by the students.

KEYWORDS: Music education in primary school. Research Topic. Collective Creation. 


\section{A Educação Musical - a legitimação de uma área do conhecimento}

A aprovação da Lei 11.769/2008, que diz respeito à obrigatoriedade do ensino da música na educação básica (BRASIL, 2008), pode nos proporcionar desafios diversos e inúmeras possibilidades de trabalhar a música na sala de aula. A música, ao ser tratada como forma de conhecimento, tem sido bastante discutida, principalmente depois da aprovação da referida Lei, que a tornou conteúdo obrigatório, mas não exclusivo do ensino da Arte.

Partindo dessas reflexões iniciais, percebemos a importância de analisarmos os textos e os documentos normativos oficiais que tratam do ensino da arte e da música na escola básica, para que possamos, de fato, com cautela, entendê-los e interpretá-los na busca de contribuir para a normatização e aplicação da Lei. Segundo Marcuschi (2008), um texto permite múltiplas interpretações, e documentos como estes não permitem qualquer interpretação para que não seja colocado em jogo seus principais objetivos. Assim, surgem reflexões sobre o tema, além de estudarmos sobre quais serão os objetivos do ensino da música na escola básica, como também, pensarmos quais os melhores caminhos a serem seguidos.

A Educação Artística foi implantada no Brasil na década de 1970, e ao refletirmos sobre a Lei 5692/71, que trata do ensino Arte/música (BRASIL, 1979), como também, com a Lei da década de 1990, Lei de Diretrizes Bases da Educação Nacional - Lei no 9.394/96, que é a vigente LDB (BRASIL, 1996), não encontramos indicações específicas das linguagens artísticas que possam integrar o campo do ensino das artes, havendo, com isso, uma referência imprecisa a respeito da área.

Assim, a primeira fala sobre o estabelecimento da obrigação na inclusão da Educação Artística nos “currículos plenos dos estabelecimentos de $1^{\circ}$ e $2^{\circ}$ Graus", de acordo com o Artigo $7^{\circ}$ da Lei 5692/71, vem ao lado da Educação Física e Programas de Saúde e da Educação Moral e Cívica (BRASIL, 1979, p. 24-25), e a segunda e atual LDB, determina que: "o ensino da arte, especialmente em suas expressões regionais, constituirá componente curricular obrigatório, nos diversos níveis da educação básica, de forma a promover o desenvolvimento cultural dos alunos" - (Lei 9394/96 - art. 26, parágrafo $2^{\circ}$ ), garantindo, assim, um espaço para a(s) arte(s) na escola, como já estabelecido com a inclusão da Educação Artística no currículo pleno em 1971. Podemos considerar então que ambas se assemelham, como também apresentam características de ambiguidade, 
uma vez que proporcionam a multiplicidade de interpretações para a expressão "ensino da arte", não havendo menção direta ao ensino da música. Devido à persistência da indefinição, se faz necessário defini-la com maior precisão (PENNA, 2014).

Devemos pensar também na formação docente para atuação na Educação Artística e/ou o "ensino da arte", ao questionarmos: Quais linguagens artísticas seriam contempladas por estes componentes curriculares? Em 1973, no campo da Educação Artística são aprovados o Parecer do Conselho Federal de Educação (CFE) no 1.284/73 e a Resolução CFE no 23/73, que trazem textos normativos a respeito do curso de licenciatura em Educação Artística, estabelecendo a licenciatura de $1^{\mathrm{o}}$ grau ou licenciatura curta, que proporcionava uma habilitação geral com uma abordagem que integrava diversas linguagens artísticas, e a licenciatura plena, que integrava uma habilitação específica (Artes Cênicas, Artes Plásticas, Música e Desenho) a essa habilitação geral (BRASIL, 1982).

Na LDB vigente, $n^{\circ}$ 9.394/96, encontramos especificações para o "ensino da arte" nos Parâmetros Curriculares Nacionais (PCN) para o Ensino Fundamental e Médio (cf. BRASIL, 1997a; 1998a; 1999). Os documentos elaborados pelo Ministério da Educação (MEC) trazem orientações oficiais para a prática pedagógica. Nos PCN, para o Ensino Fundamental (divididos em dois conjuntos de documentos: o primeiro de $1^{\mathrm{a}}$ à $4^{\mathrm{a}}$ série, e o segundo de $5^{\mathrm{a}}$ à $8^{\mathrm{a}}$ série - ampliado posteriormente para 9 anos), foram publicados em 1997 e em 1998, propondo quatro modalidades artísticas: Artes Visuais, Música, Teatro e Dança. No entanto, não há clareza de quais modalidades seriam trabalhadas e nem de como abordá-las na escola (PENNA, 2014).

Nessa perspectiva, as decisões relacionadas às diferentes linguagens artísticas ficam sob a responsabilidade de cada instituição de ensino. Há ainda uma falta de clareza quanto à formação do professor de Arte para atuar neste contexto, pois além do ensino e aprendizagem de todas as áreas de conhecimento (incluindo as artes) estarem a cargo do professor unidocente, os PCN configuram-se flexíveis ao permitirem uma leitura polivalente sob a proposta de quatros modalidades artísticas diferentes. Portanto, há outras séries de questões que dizem respeito aos avanços e/ou retrocessos relacionados ao tema, e para melhor esclarecermos questões que englobam a formação para atuação docente no campo da Educação Básica, seria necessário um maior aprofundamento nas discussões. O objetivo deste trabalho é discutir questões relacionadas ao ensino de música na escola básica, fundamentar e melhor situar o leitor a respeito do relato de experiência em questão. 
Em relação a permanência da polivalência no ensino de artes, podemos percebêla relacionada à referida Lei na década de 70, quando o Parecer CFE no 540/77 diz claramente que "A Educação Artística não se dirigirá, pois, a um determinado terreno estético", e que "A partir da série escolhida [...] as escolas deverão contar com professores de Educação Artística, preferencialmente polivalente no $1^{\circ}$ grau" (BRASIL, 1982, p. 12). Esta polivalência, como também, a não garantia do ensino da música, permanece mesmo depois da referida Lei na década de 90, a LDB, pois os termos legais e normativos federais podem ser articulados a nível estadual e municipal, possibilitando um espaço de autonomia para que a própria escola decida quais áreas de conhecimento irão ser aderidas ao "elaborar e executar sua proposta pedagógica" (Lei 9.394/96, art. 12), podendo ou não, incluir um trabalho específico em música (PENNA, 2014).

A Educação Musical na escola, através da prática da Educação Artística e do "ensino de arte" pode até apresentar alguns problemas, no entanto, acreditamos que sua implantação proporciona um desafio a ampliar cada vez mais as suas práticas pedagógicas, tornando-se mais acessível e fazendo parte da formação de todas as crianças que têm acesso à Educação Básica. Um grande desafio é impedir que a presença da música na Escola Básica se dê apenas nos momentos de cantar o Hino Nacional, na realização de festas e/ou em datas comemorativas, intervalos, atividades extracurriculares ou acompanhamento de atividades cotidianas da educação na infância (PENNA; MELO, 2006). Precisamos fazer com que o ensino e aprendizagem de música, neste contexto, torne-se cada vez mais efetivo e seja parte significativa para a formação dos alunos, isso implica em agregar esse ensino como caráter curricular em sala de aula.

\section{O ensino da música como contribuição para a formação do ser}

Para que possamos ter o ensino da música em sala de aula, é preciso que, além de ter clareza sobre as determinações legais na prática, possamos visar propostas para a implementação da Lei 11.769/2008, que incluam a criação de cargos públicos de professor de música, a serem ocupados através de concursos públicos específicos (SOUZA, 2010, p. 89). Para isso, precisaríamos de um número suficiente de professores especialistas formados, com práticas significativas e capazes de ocupar essas funções, efetivando, assim, um espaço para a música no currículo escolar. 
Segundo Queiroz (2013), a música como prática social é constituída por aspectos estruturais e estéticos, incluindo elementos que caracterizem um sistema cultural, que é compartilhada pelos seus praticantes de forma individual e/ou coletivamente. Ao afirmar que "a diversidade permite ao aluno a construção de hipóteses sobre o lugar de cada obra no patrimônio musical da humanidade, aprimorando sua condição de avaliar a qualidade das próprias produções e as dos outros" (BRASIL, 1997, p. 53), os PCN estabelecem uma proposta de ensino de música fundamentada na experiência da expressão musical por meio de processos de apreciação, interpretação e criação, sugerindo que o trabalho de formação musical nas escolas de Educação Básica seja conduzido pela diversidade de repertórios, locais, práticas musicais e sujeitos.

Entendendo a escola como fenômeno cultural estabelecida socialmente para a formação do sujeito, vemos a Educação Musical na Educação Básica como forma de contribuição para o desenvolvimento e formação do ser, a partir da sua ampliação das percepções estéticas, de suas várias formas de ver o mundo, de suas inúmeras possibilidades de expressão e de seu conhecimento cultural.

Apesar do caráter de obrigatoriedade do ensino da música na escola básica, conforme preconiza a Lei $11.769 / 2008$, abrindo diversas possibilidades, dependemos muito das conquistas de cada contexto para sua efetivação, pois mesmo que os documentos legais assegurem o ensino da música como conteúdo obrigatório - mas não exclusivo do ensino da Arte - não nos garantem se o ensino será desenvolvido com qualidade, eficácia e transformações de práticas pedagógicas.

Visualizamos a Educação Musical e a atuação do especialista (seu ensino na sala de aula) como forma de contribuição para a formação do ser, e que este profissional tenha como seu objetivo maior atribuir sentidos e significados ao universo da criança, dentro ou fora da escola, proporcionando uma aproximação por meio de vivências diversas. Acreditamos, assim, que o principal objetivo do ensino de música na escola básica não é o de formar futuros músicos, e, sim, formar cidadãos que possam ser capazes de estabelecerem diferentes relações com o fazer musical, contribuindo para a formação de uma comunidade de aprendizes que vivenciaram a música na escola por meio de diferentes perspectivas. 


\section{Tema de pesquisa - uma proposta metodológica provocadora da autonomia}

Como procedimento metodológico, adotado pela equipe do Núcleo de Educação da Infância-Colégio de Aplicação da Universidade Federal do Rio Grande do Norte NEI-CAp/UFRN, o Tema de Pesquisa pretende articular três dimensões básicas nos processos de ensinar e aprender: o conhecimento das áreas de conteúdo, que se quer tornar disponível às crianças; o contexto sociocultural das crianças; e os aspectos vinculados diretamente à aprendizagem - normas, conhecimentos, valores e habilidades da cultura e da sociedade (VICTOR, 2012). Articulando com os saberes musicais, o Tema de Pesquisa é trazido para as aulas de música dos anos iniciais do Ensino Fundamental quando as crianças têm a autonomia de escolher os temas que desejam aprender, organizando os momentos pedagógico-musicais, consolidando os processos criativos de ensino e aprendizagem musicais.

A educação cultural que se pretende com a Proposta Triangular é uma educação crítica do conhecimento construído pelo próprio aluno, com a mediação do professor, acerca do mundo visual e não uma "educação bancária" (BARBOSA, 1998a, p. 40).

Mosca afirma que ensinar música não é transferir conteúdos, mas sim uma prática vivida na música, na promoção da aproximação musical dos educandos. Para a autora, música é vida e "acompanha o percurso da história do homem, tomando forma nas grandes civilizações e imprimindo a marca dos povos, fazendo-se presente em todas as culturas" (MOSCA, 2009, p.36).

Após a escolha do tema - realizado coletivamente pelas crianças - temos os momentos de imersão no tema: o estudo da realidade (ER), a organização do conhecimento (OC) e a aplicação do conhecimento (AC) - que se tornam momentos em movimento no decorrer dos processos.

O NEI-CAp possuiu, no ano letivo de 2014, 16 (dezesseis) turmas - da Creche ao Ensino Fundamental I. Trataremos neste trabalho sobre as turmas do Ensino Fundamental I matutino: um $2^{\circ}$ ano constituído por 18 (dezoito) crianças de 7 anos de idade; e um $3^{\circ}$ ano, por 19 (dezenove) crianças de 8 anos de idade. Destacamos aqui, também, que não só no Ensino Fundamental I matutino, mas em todas as 16 (dezesseis) turmas da escola, há crianças com Necessidades Educacionais Especiais/NEE.

As aulas de músicas ficam a cargo de uma professora especialista em música, em trabalho de equipe com mais três professores bolsistas, alunos do curso de licenciatura 
em Música da Escola de Música da UFRN. Estes participaram de forma efetiva e direta de todo o processo, desde a construção à apresentação do recital. Nossos encontros com as turmas do NEI-CAp eram feitos semanalmente, com 45 (quarenta e cinco) minutos cada, denominados Aula de Música. As crianças das turmas vinham às aulas de música acompanhadas de suas/seus professoras/es unidocentes, que tiveram aulas, inicialmente, com a professora idealizadora e coordenadora de um projeto intitulado "Música e Movimento". Com o afastamento desta professora, as aulas deram continuidade posteriormente com uma professora especialista substituta, que desenvolveu o trabalho juntamente com os bolsistas selecionados por meio do projeto mencionado. Ao trabalharmos com música e movimento, acreditamos no estímulo e na liberdade criadora, em que a inclusão deve acontecer em todos os aspectos - físico, cognitivo, social e emocional, e que devemos ter satisfação e simplicidade ao trabalhar na colaboração e na coletividade. Como nos diz Orff (1978), seduzir pela música, encontrar na complexidade novos caminhos a seguir, elevar a estima de nossos educandos e promover o humano.

\section{O recital "Você conhece esse tal The Beatles?" - Uma proposta desafiante e compensadora}

O tema de pesquisa escolhido em assembleia pelos alunos do $2^{\circ}$ e $3^{\circ}$ anos matutino foi a banda inglesa de rock The Beatles. É importante ressaltar que a escolha do tema é o cume de um processo que envolve o engajamento dos alunos e é realizado a partir de levantamento de possibilidades de temas dentro da própria sala de aula e com o auxílio dos/as professores/as. Diversos temas são apontados pelos alunos, que, democraticamente, expressam seus desejos de pesquisa. Livremente, os simpatizantes pelos temas despontam, agrupam-se e os/as professores/as estimulam os integrantes dos grupos a se questionarem acerca das motivações pela pesquisa e quais as contribuições que o referido tema pode trazer para a turma. Após estes questionamentos, os alunos devem elaborar o que poderíamos chamar de "campanha para defender o tema" diante de todos e, assim, provocar a discussão e a votação que decidirá, enfim, qual o mote que será pesquisado por todos.

O momento da decisão pelo tema é chamado de assembleia. Todos os alunos das turmas envolvidas se reúnem no auditório da escola para a votação. Antes, cada grupo responsável por defender o tema apresenta a sua proposta e explica a relevância de seu tema de pesquisa, afim de despertar o interesse nos demais alunos. Ao final das defesas, 
ocorre a eleição. Na ocasião da escolha pelos Beatles, os outros temas defendidos foram a música Pop, a Bossa Nova e a Música Africana.

Terminada a campanha e a eleição, começam os trabalhos dos/as professores/as especialistas na organização e no planejamento das aulas de música, em uma tentativa constante de enquadramento do tema escolhido pelos alunos e inserção dos conteúdos musicais e das temáticas concernentes ao nível de cada turma. Nesse período, contamos muito com a colaboração dos/as professores/as unidocentes das turmas que acompanham no cotidiano o andamento das pesquisas que devem ser realizadas na sala de aulas e em casa com o auxílio dos pais.

Pensando nas aulas de música, voltamo-nos para o repertório do objeto da pesquisa com o intuito de encontrarmos obras que atendessem às necessidades pedagógicas de nossas aulas. Com o objetivo de abordar aspectos musicológicos (ritmo, forma musical, partes da música, linguagem musical) e etnomusicológicos (formação da banda, história do fenômeno musical, instrumentos utilizados), sistematizamos as aulas a partir da apreciação, contextualização e produção, baseando-nos na proposta triangular de ensino da arte de Ana Mae Barbosa, também presente nos Parâmetros Curriculares Nacionais.

\footnotetext{
A Proposta Triangular [...] é de natureza epistemológica, ao designar aos componentes do ensino/aprendizagem por três ações mentalmente e sensorialmente básicas, quais sejam: criação (fazer artístico), leitura da obra de arte e contextualização (BARBOSA, 1998a, p. 35).
}

Assim, buscamos despertar nos alunos não somente o conhecer e a criação musical, mas a associação com outras áreas do conhecimento e com outras linguagens artísticas. Para a autora, "não se tratam de fases da aprendizagem, mas de processos mentais que se interligam para operar a rede cognitiva da aprendizagem" (BARBOSA, 1998a, p. 40).

Na primeira aula, exibimos uma apresentação em Datashow com informações específicas sobre os Beatles, fotos dos músicos, imagens dos shows, discografia da banda e vídeos de clipes de algumas canções icônicas. Nas aulas seguintes, preocupamo-nos com o dinamismo, a criatividade e a participação dos alunos.

Realizamos, então, uma apreciação participativa da música "She Loves You", utilizando uma espécie de "aranha" feita com elásticos em que cada aluno segurava uma "perna" da aranha e enquanto escutava a música, criava e realizava movimentos segundo o ritmo e a dinâmica da mesma. Em alguns momentos, os movimentos eram livres e improvisados, em outros, os movimentos eram guiados por algum professor ou aluno, 
enfatizando sempre as mudanças entre as partes da música. A associação do movimento à aprendizagem musical muito tem a ver com o pensamento de Jaques-Dalcroze, que "pretendia desvencilhar o aluno de uma prática mecânica no aprendizado da música [...] estabelecendo relações entre estes dois [corpo e mente] através de uma educação musical baseada na audição e atuação do corpo" (MARIANI, 2011, p. 31).

Em uma outra aula, com o objetivo de trabalharmos a letra da música "Hello, Goodbye" sugerimos a viagem à "terra dos contrários" onde tudo era encarado como inverso. Assim, com figuras (imagens) e seu significado correspondente em inglês, brincamos com o universo dos antônimos até chegarmos na música dos Beatles que mostra um diálogo entre pessoas que pensam inversamente. Com a colaboração dos alunos, criamos coletivamente uma coreografia para dois grupos que interagiam conforme o desenrolar da música acontecia. Nela, o movimento e a criatividade foram a grande marca, além da consciência rítmica que, segundo Dalcroze, é "resultado de uma experiência corporal” (MARIANI, 2011, p. 31).

Com os alunos do terceiro ano, trabalhamos, além das músicas já referidas, outras que apresentavam a possibilidade de aprendizagem instrumental por meio delas. Foi o caso de "Yellow Submarine", "She Loves You" e "Twist and Shout" para as quais foram criados arranjos de flauta doce, xilofones e metalofone, instrumentos recomendados por Carl Orff como significativos na aprendizagem musical e no movimento (BONA, 2011, p. 145). O caráter predominantemente instrumental das aulas com esta turma não impediu que preparássemos atividades iniciais envolvendo os alunos com a obra antes de tocá-la. Trabalhamos aspectos importantes como a forma da música pop rock tão característica da banda de Liverpool, a identificação dos timbres instrumentais caracterizadores de suas canções, as partes da música (introdução, estrofes, refrão, intermezzo, finalização), bem como os ritmos e andamentos.

A preocupação de tornar a aprendizagem musical criativa e significativa para todos os alunos sempre permeou os nossos planejamentos, tendo em vista que nem todos os alunos tinham aproximação da cultura privilegiada pelos Beatles ou não demonstravam interesse inicial para tanto. A questão da língua inglesa não foi uma barreira difícil de transpor, já que contamos com a contribuição da professora especialista de inglês, que prontamente se disponibilizou em ajudar-nos, fazendo-se presente em algumas aulas e/ou esclarecendo algumas dúvidas. A possibilidade de estabelecer parceria dentro de um tema que consideramos tão interdisciplinar foi inevitável. O resultado desse trabalho culminou 
com um belo recital em que as crianças, coletivamente e com muito esmero, trabalharam para apresentar aspectos de sua aprendizagem em forma de musical.

A música escolhida pelo $2^{\circ}$ ano para a apresentação foi "Hello, Goodbye". Para ela, montamos uma coreografia contando com a criatividade dos alunos que participaram ativamente do processo de criação, em que cantaram e dançaram a canção dos Beatles com muito entusiasmo. Atribuímos tal entusiasmo ao fato da canção ter feito parte do cotidiano da turma desde a proposta da "terra dos contrários". Essa aula marcou tanto os alunos, que eles insistiram em uma recriação e repetição das práticas nas aulas seguintes.

Figura 1: Turma do $2^{\circ}$ ano - Apresentação de "Hello, Goodbye".

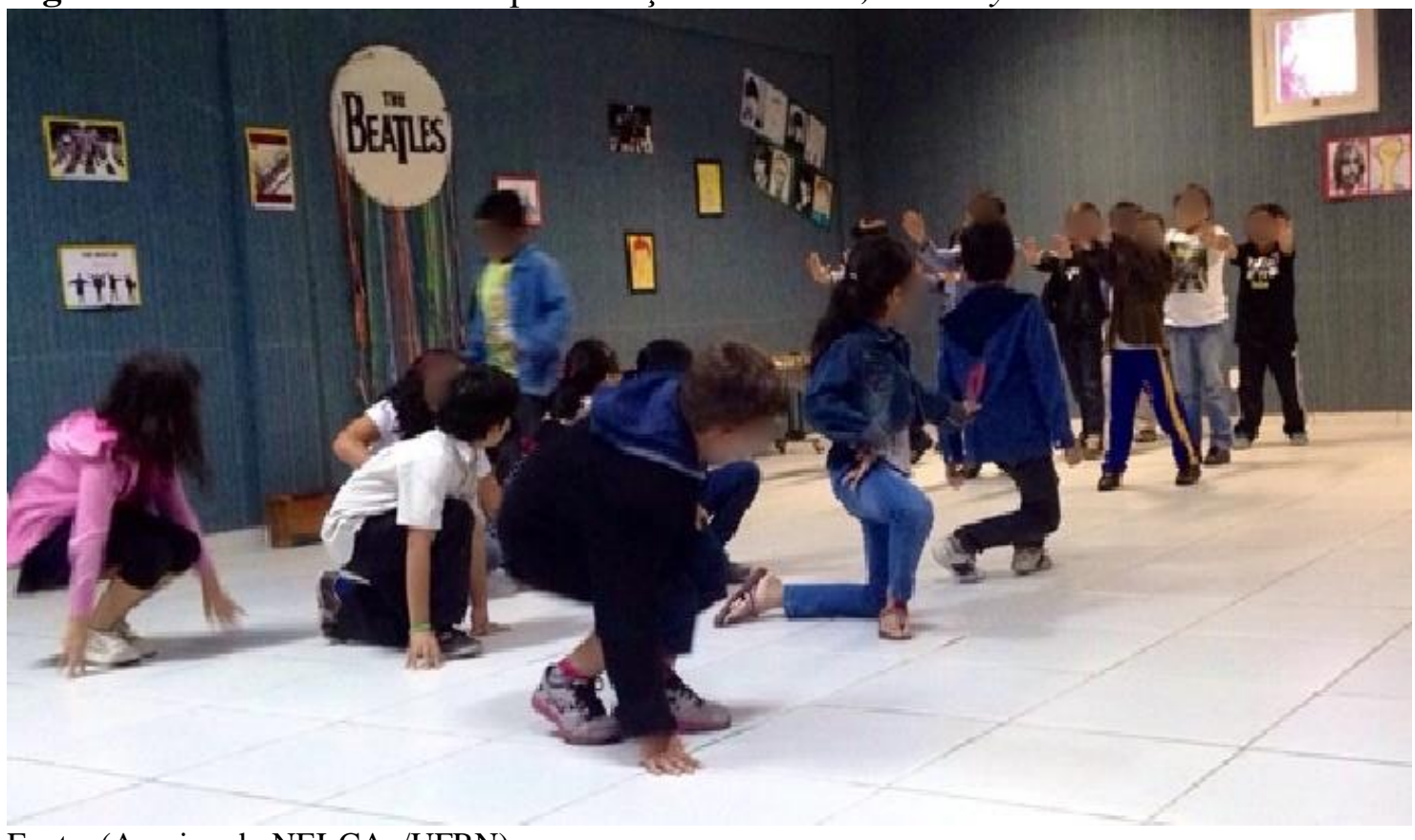

Fonte: (Arquivo do NEI-CAp/UFRN)

Com a turma do terceiro ano, trabalhamos com a flauta doce excertos de duas obras, como dito anteriormente: "Yellow Submarine" e "She Loves You". Compreendendo, porém, que não estaria tão em consonância com a proposta de um musical uma apresentação que se resumisse a tocar frases musicais em instrumentos, propusemos incrementar a cena com uma certa coreografia, que foi criada colaborativa (ABREU, 2003) e coletivamente. Assim, a turma passou a iniciar sua performance entrando em cena. Ao se posicionarem, finalizaram a primeira música e iniciaram imediatamente "She Loves You". 
Figura 2: Turma do $3^{\circ}$ ano - Apresentação de "Yellow submarine" e "She Loves You".

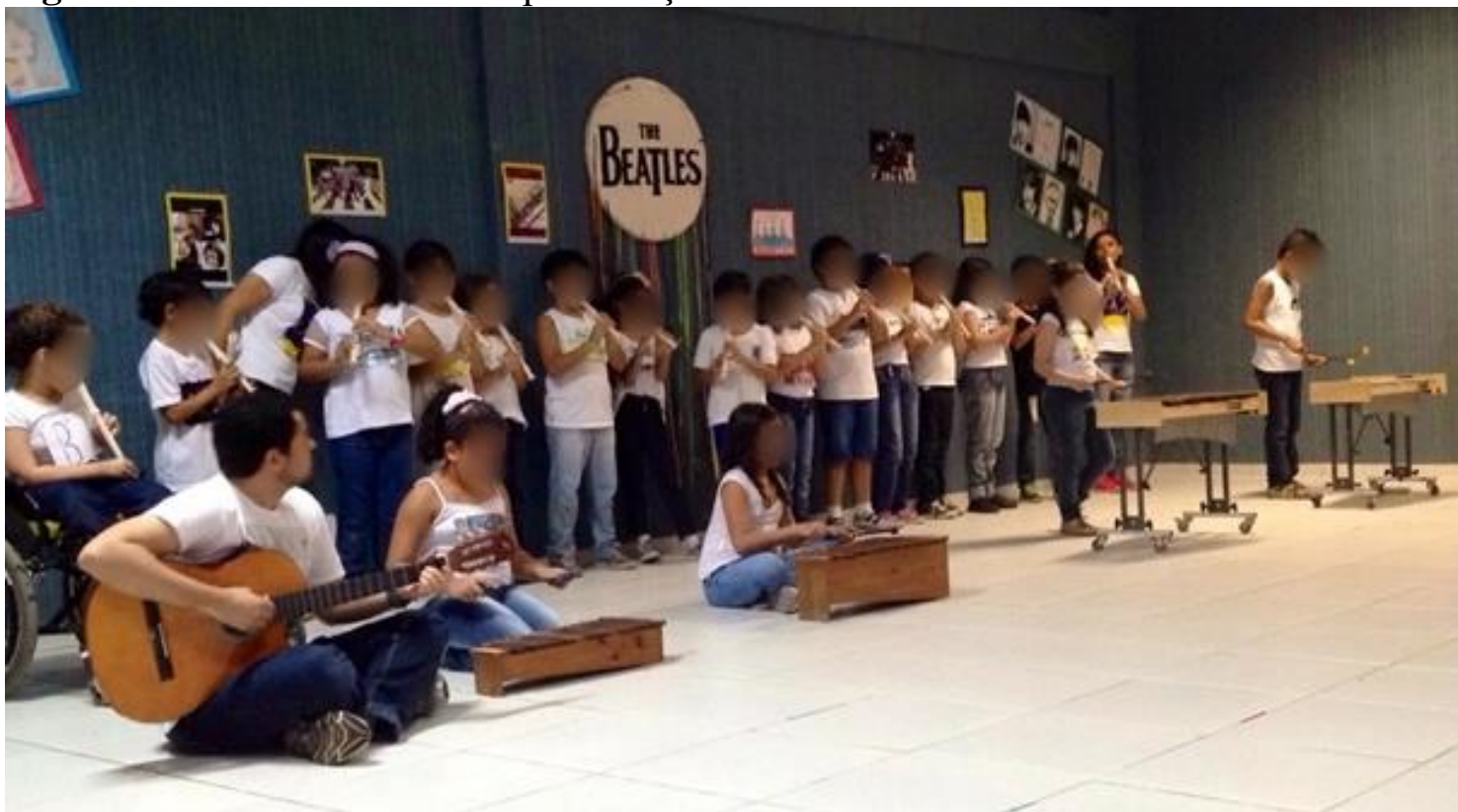

Fonte: (Arquivo do NEI-CAp/UFRN).

O encerramento da nossa apresentação musical foi com a música "Twist and Shout", com a participação dos alunos das duas turmas juntas. Enquanto os alunos do $3^{\circ}$ Ano tocavam e cantavam, os alunos do $2^{\circ}$ Ano realizavam uma coreografia com a "aranha elástica", que, para a ocasião da apresentação, ganhou uma produção visual inspiradora dos alunos que desenharam e pintaram os Beatles, tornando-se um elemento surpresa para o público ao final da apresentação, agregando ainda mais valor às linguagens artísticas envolvidas.

Figura 3: crianças dos $2^{\circ}$ e $3^{\circ}$ anos - Apresentação de "Twist and Shout" - coreografia com a "aranha elástica".

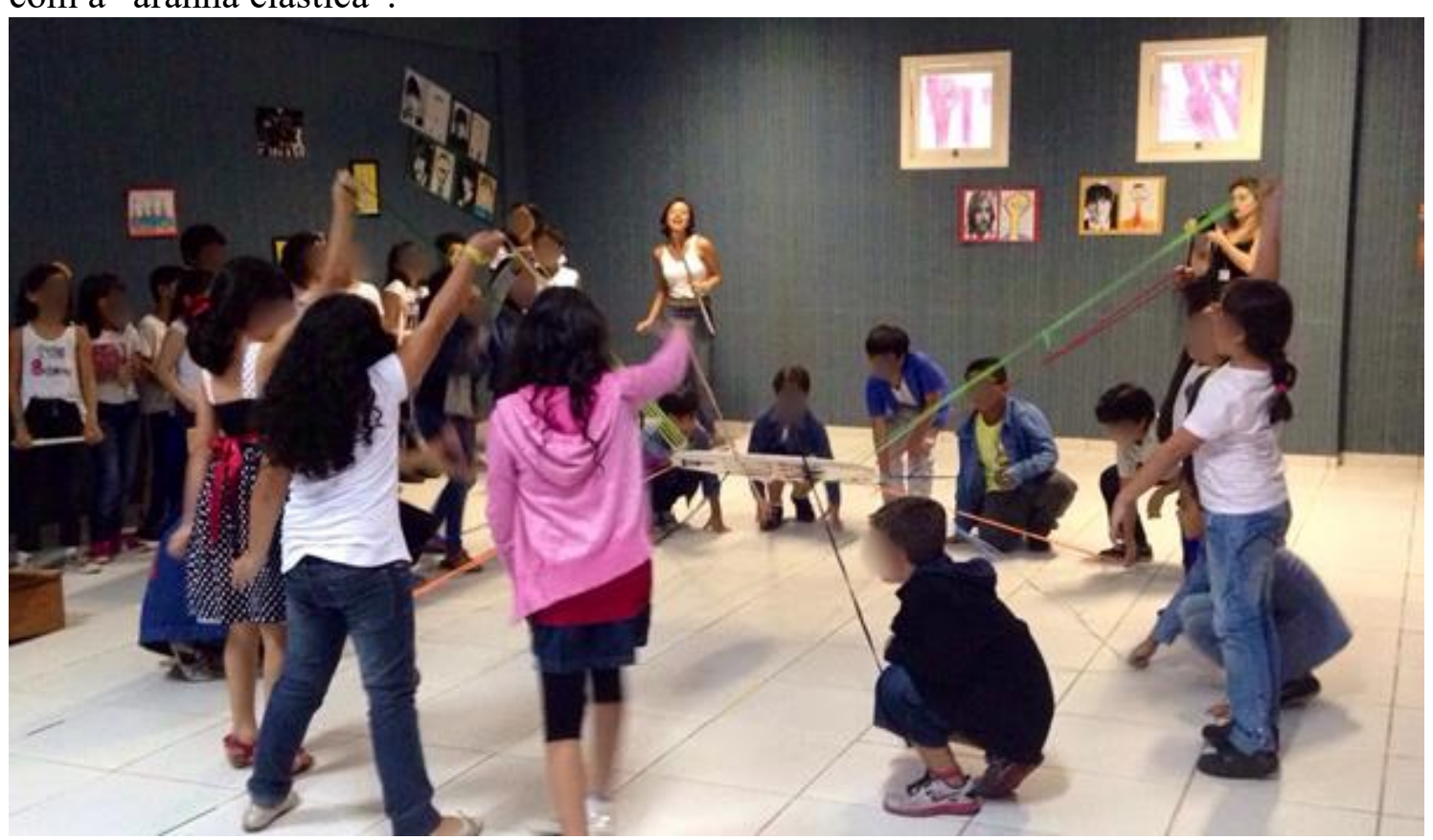

Fonte: (Arquivo do NEI-CAp/UFRN). 
Figura 4: crianças dos $2^{\circ}$ e $3^{\circ}$ anos - Final da apresentação de "Twist and Shout", mostrando a produção visual feita colaborativa e coletivamente pelos alunos.

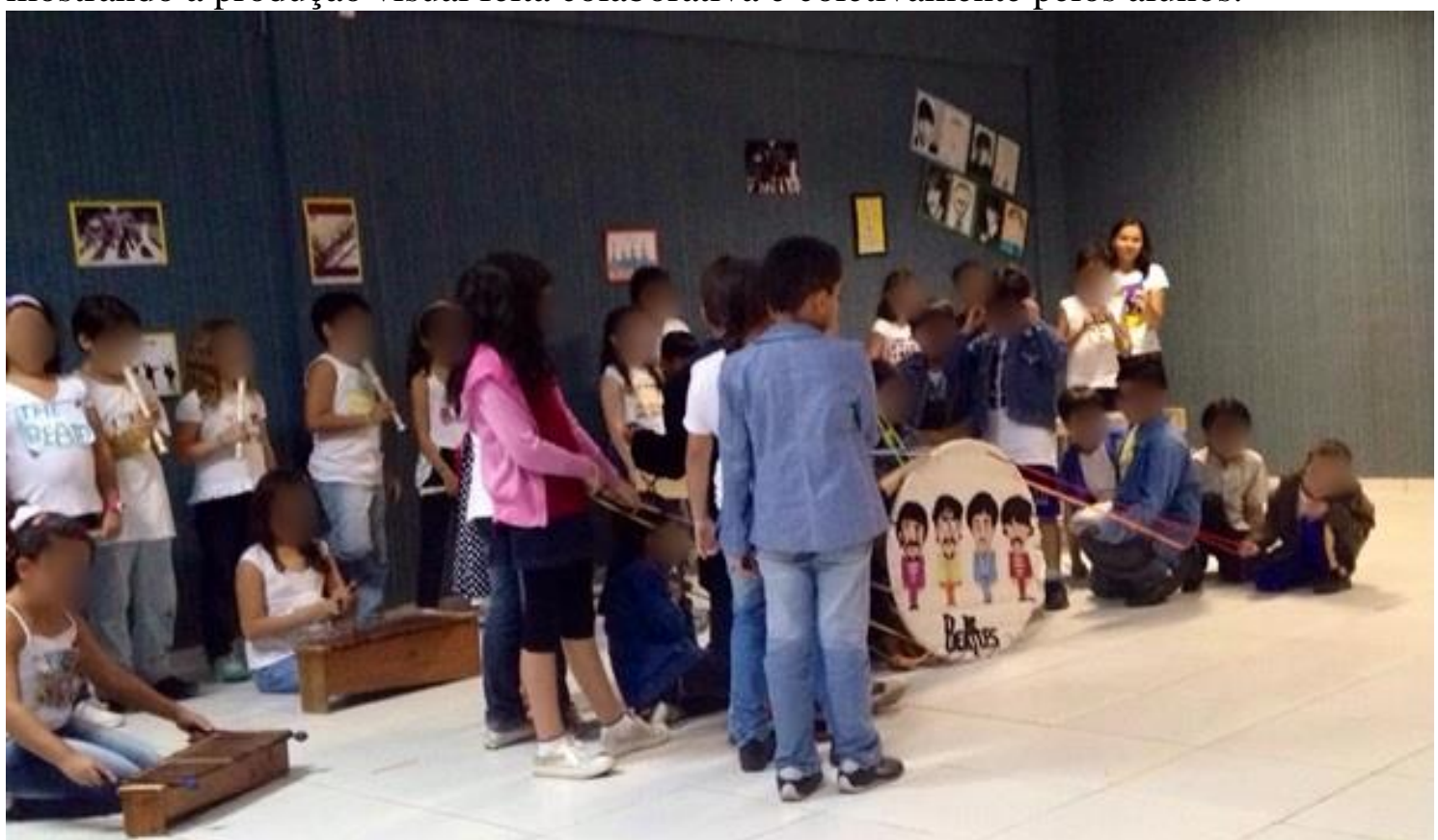

Fonte: (Arquivo do NEI-CAp/UFRN).

\section{Considerações finais}

Apresentar um recital em forma de musical não foi uma maneira de simplesmente coroar a finalização de um conteúdo de pesquisa, mas objetivamos promover a apresentação de um produto musical em um processo de criação colaborativa (ABREU, 2003) e coletiva, a partir das vivências das turmas envolvidas. Bem como pretendemos, com essa experiência, compartilhar conhecimentos sobre os Beatles como banda, estilo musical, instrumentação e produto cultural, constituir o senso estético dos participantes, partindo do envolvimento nas atividades de ensaios e apresentação; formar uma plateia, a partir de hábitos de assistir espetáculos musicais; apresentar montagens coletivas e interdisciplinares (música, língua, dança, artes visuais); e aproximar os participantes e plateia de diferentes contextos musicais, a partir da apreciação, (re)criação e contextualização.

Ao trazermos as crianças como criadoras e protagonistas de um recital de música, desejávamos que elas se percebessem atuantes nos processos de aprender e ensinar música e, a partir do criar e do fazer artístico, pudessem expressar-se musicalmente, avançando em seus conhecimentos musicais. Esperávamos também o despertar de um senso estético dos participantes - crianças, professores e familiares - que, compartilhando emoções e conhecimentos, pudessem valorizar a música na Escola de Educação Básica, 
compreendendo-a como linguagem de conhecimento, em um trabalho realizado por especialistas com formação específica. Quanto aos bolsistas - professores de música em formação - tiveram a oportunidade de desenvolver-se profissionalmente ao vivenciarem os processos de contextualização, apreciação, colaboração, criação e fazer artístico, tendo a música como eixo de um trabalho interdisciplinar. Para sua formação, é de extrema importância momentos em que possam (re)significar seus saberes musicais, suas práticas pedagógicas, a partir da ação-reflexão-ação.

Como educadores musicais que atuam com o ensino de música na Educação Básica, não podemos permitir que o trabalho pedagógico com o ensino de música seja esporádico e superficial. Precisamos, sim, fortalecer o nosso compromisso com a Educação Básica, realizando estudos que discutam nossa prática pedagógica nas escolas, e que possam descrever realidades, além de propor alternativas para este contexto educativo, mesmo havendo reais desafios para a educação musical, tais como - turmas numerosas, baixos salários, falta de recursos e de materiais, desvalorização do professor, indisciplina, etc..

Assim, precisamos ocupar o espaço da escola básica de forma efetiva e com práticas significativas e renovadoras, para que possamos firmar o ensino da música neste contexto, além de conquistar reconhecimento e valorização. As leis e termos normativos não são capazes de garantir mudanças no cotidiano escolar, mas, ao atuarmos nesse contexto, como especialistas, temos consciência da necessidade de desenvolver um trabalho competente à busca de contribuir para que a obrigatoriedade do ensino de música nas escolas possa ter, de fato, efeitos positivos e reafirme sua presença no ambiente educacional.

\section{REFERÊNCIAS BIBLIOGRÁFICAS}

ABREU, L. A. Processo colaborativo: relato e reflexões sobre uma experiência de criação. Cadernos da Escola Livre de Teatro de Santo André, Santo André, n. 0, p. 33-41, 2003. Disponível em:

$<$ http://escolalivredeteatro.blogspot.com/2006/01/processo-colaborativorelato-ereflexo.html>. Acesso em: 05 abr. 2016.

BARBOSA, A. M. Tópicos Utópicos. Belo Horizonte: C/Arte, 1998a.

BONA, M. Carl Orff - um compositor em cena in Pedagogias em Educação Musical, Org.: MATEIRO, Teresa; ILARI, Beatriz. Curitiba: Ibpex, 2011, p. 125-156. 
BRASIL. Lei ${ }^{\circ} 11.769$, de 18 de agosto de 2008. Altera a Lei $\mathbf{n}^{\mathbf{0}}$ 9.394, de 20 de dezembro de 1996... para dispor sobre a obrigatoriedade do ensino da música na educação básica. Diário Oficial da União, Brasília, ano CXLV, n. 159, seção 1, p. 1,19 ago. 2008. Disponível em:

$<$ https://www.in.gov.br/imprensa/visualiza/index.jsp?jornal=\&pagina=1\&data=19/08/2 008>. Acesso em: 2 fev. 2016.

BRASIL. Lei n ${ }^{\circ}$ 9.394, de 20 de dezembro de 1996. Estabelece as diretrizes e bases da educação nacional. Brasília, 1996. Disponível em:

<http://www6.senado.gov.br/legislacao/ListaPublicacoes.action?id=102480>. Acesso em: 2 fev. 2016.

BRASIL. Ministério da Educação e Cultura. Departamento de Ensino Fundamental. Do ensino de $1^{\circ}$ grau: legislação e pareceres. Brasília, 1979. Incluindo Lei 4024/61, Lei 5692/71 e Parecer CFE n ${ }^{\circ}$ 540/77.

BRASIL. Ministério da Educação e Cultura. Secretaria de Ensino de $1^{\circ}$ e $2^{\circ}$ Graus. Educação Artística: leis e pareceres. Brasília, 1982, Incluindo Resolução CFE no 23/73.

BRASIL. Ministério da Educação e do Desporto. Secretaria de Educação Fundamental. Parâmetros curriculares nacionais: apresentação dos temas transversais, ética. Brasília: MEC/ SEF, 1997a.

BRASIL. Ministério da Educação e do Desporto. Secretaria de Educação Fundamental. Parâmetros curriculares nacionais: arte. Brasília, 1997c.

BRASIL. Ministério da Educação e do Desporto. Secretaria de Educação Fundamental. Parâmetros curriculares nacionais ( $5^{\mathrm{a}}$ a $8^{\mathrm{a}}$ séries $)$ : arte. Brasília, 1998.

MARCUSCHI, L. A. Produção textual, análise de gêneros e compreensão. São Paulo: Parábola, 2008.

MARIANI, S. Émile Jaques-Dalcroze - a música e o movimento in Pedagogias em Educação Musical, Org.: MATEIRO, Teresa; ILARI, Beatriz. Curitiba: Ibpex, 2011, p. $25-54$.

MOSCA, M. O. Como se fosse brincadeira de roda: a ciranda da ludopoiese para uma educação musical humanescente. Dissertação - (Mestrado em Educação) Universidade Federal do Rio Grande do Norte, Natal, 2009.

ORFF, C. The Shulwerk. New York: Schott Music Corp., 1978.

PENNA, M. Lei 11.769/2008 e a Música na Educação Básica: quadro histórico, perspectivas e desafios. InterMeio: revista do Programa de Pós-Graduação em Educação, Campo Grande - MS, v. 19, n. 37, p.53-75, jan/jun. 2013. Semestral.

PENNA, M. Música(s) e seu ensino. 2. Ed. rev. E ampl. Porto Alegre: Sulina, 2014. 
PENNA, M; MELO, R. A. Música na educação infantil: cenas cotidianas em instituições municipais de Campina Grande - PB. In: ENCONTRO ANUAL DA ABEM, 15., 2006, João Pessoa. Anais.... João Pessoa: UFPB, 2006. p. 472-478. CDrom.

QUEIROZ, L. R. S. Escola, cultura, diversidade e educação musical: diálogos da contemporaneidade. InterMeio: revista do Programa de Pós-Graduação em Educação, Campo Grande - MS, v. 19, n. 37, p.95-124, jan/jun. 2013. Semestral.

SOUZA, J. (Coord.). Audiência pública sobre políticas de implantação da lei federal $\mathrm{n}^{\circ}$ 11.769/08 na Assembleia Legislativa do Estado do Rio Grande do Sul. Revista da ABEM, Porto Alegre, n. 23, p. 84-94, mar. 2010.

VICTOR, A. C. S. Ensinando e aprendendo a ler na escola infantil: reflexões sobre o saber-fazer de uma professora. Práxis Educacional, Vitória da Conquista, v. 8, n. 12, p. 185-198, jan./jun. 2012.

Recebido em: 22/02/2016

Aprovado em: 28/04/2016 